\title{
Enhancement of Naphthalene Biodegradation by Sulfate Application in Brackish Subsurface Systems
}

\author{
Saeid Shafieiyoun \\ saeid.s@qu.edu.qa \\ Department of Civil and Architectural Engineering, Qatar University, Doha, Qatar \\ Reem Ismail \\ ri1607496@qu.edu.qa \\ Department of Civil and Architectural Engineering, Qatar University, Doha, Qatar \\ Riyadh I. Al-Rauosh \\ riyadh@qu.edu.qa \\ Department of Civil and Architectural Engineering, Qatar University, Doha, Qatar
}

\begin{abstract}
Anaerobic biodegradation is the most dominant mechanism in the petroleum hydrocarbon contaminated subsurface systems. Due to depletion of terminal electron acceptors such as sulfate, anaerobic degradation of organic contaminants can be restricted. Hence, engineered sulfate application has been proposed as an effective remediation strategy to enhance the activities of sulfate reducer bacteria (SRB) in the contaminated subsurface systems. However, biodegradation process is significantly affected by environmental conditions and sulfate application in the contaminated saline and brackish coastal regions is unknown. A series of flow-through reactors (FTRs) representative of dynamic anaerobic subsurface conditions were conducted using undisturbed soil samples collected from brackish (semi)-arid coastal environments in Qatar. Dissolved naphthalene as one of the most dominant petroleum hydrocarbons that can be found in most of the contaminated sites was injected into FTRs under different salinity conditions. The relevant geochemical indicators as well as soil adsorption and dissolved phase concentrations were measured. The results confirmed development of reducing conditions as well as SRB activity under experimental conditions. Salinity did not restrict bioremediation and dissolved naphthalene degradation was more stable and enhanced under brackish water conditions because microbial cultures within the undisturbed soil were adapted to the brackish water conditions at the field sampling environment. This paper will provide an overview of the flow-through experiments and key findings.
\end{abstract}

Keywords: Naphthalene biodegradation; Sulfate reducing conditions; Salinity; Brackish groundwater

\section{INTRODUCTION}

Release of petroleum hydrocarbons in the subsurface systems is one the most important environmental issues that can result in soil and groundwater contamination (Al-Raoush, 2014, Shafieiyoun et al., 2018). Anaerobic biodegradation is the dominant process in contaminated systems but due to depletion of dissolved oxygen (DO) and other electron acceptors during natural attenuation, remediation will last for a long period of time. Sulfate injection is one of the recent treatment methodologies to enhance biodegradation mechanisms. Previous studies indicate that microbial activities can be 
limited in the saline and brackish environment (Thamer et al., 2013; Abed et al., 2015). Hence, in this study the effect of salinity on engineered sulfate injection as a remediation strategy was investigated.

\section{MATERIALS AND METHODS}

None-contaminated undisturbed soil samples were collected from a shoreline known as Sumaysimah beach in the State of Qatar. Groundwater $\mathrm{pH}$ and EC values at the sampling location were $\sim 7.5$ and $\sim 4000 \mu \mathrm{S} / \mathrm{cm}$ that categorized it in the range of brackish water.

Six flow-through reactors (FTRs) were constructed similar to Pallud et al. (2007) by a Plexiglas ring of $10 \mathrm{~cm}$ length and $4.7 \mathrm{~cm}$ inside diameter. The nominal pore volume $(\mathrm{PV})$ was $52 \mathrm{~mL}$. FTRs were flushed upward by a peristaltic pump at a nominal rate of 2.7 $\mathrm{mL} / \mathrm{hr}$ to be in the range of groundwater flow rate at the sampling location. The influent and effluent solutions were sampled regularly and analyzed for the concentrations of naphthalene and sulfate. In addition, $\mathrm{pH}, \mathrm{EC}, \mathrm{Eh}$, and $\mathrm{DO}$ of the samples were also measured.

FTRs were injected by a synthetic influent solution containing back ground levels of $\mathrm{MgCl}_{2}(89 \mathrm{mg} / \mathrm{L}), \mathrm{KCl}(24 \mathrm{mg} / \mathrm{L})$, and $\mathrm{CaCl}_{2} \cdot \mathrm{H}_{2} \mathrm{O}(243 \mathrm{mg} / \mathrm{L})$ on the basis of groundwater analyses were added that were dissolved in argon purged Milli-Q water $(\mathrm{DO}<0.8$ $\mathrm{mg} / \mathrm{L}$ ). Dissolved naphthalene concentration in the influent solution was $4 \mathrm{mg} / \mathrm{L}$ during the first injection episode but later during the second injection episode increased to 13 $\mathrm{mg} / \mathrm{L}$ to explore the effects of higher levels of contamination on microbial activities. Sulfate concentration during both injection episodes was $150 \mathrm{mg} / \mathrm{L}$ to be more than stoichiometric requirement for the biodegradation process. The influent solution was transferred into the $1 \mathrm{~L}$ Tedlar bags which served as the reservoir for the FTRs.

Two FTRs were flushed by a low salinity argon purged influent solution containing background nutrients, sulfate, and naphthalene (identified as LS1 and LS2) and two FTRs were flushed by a high salinity argon purged influent solution containing background nutrients, $1300 \mathrm{mg} / \mathrm{L} \mathrm{NaCl}$, sulfate, and naphthalene to be in the range of brackish water similar to the sampling location (identified as BW1, BW2). To investigate the soil adsorption, one FTR (identified as Biocide) was flushed identical to the LS FTRs and just $275 \mathrm{mg} / \mathrm{L} \mathrm{HgCl} 2$ biocide (Van De Graaf, 1995) was added to the influent solution to inhibit biodegradation. The last FTR was flushed identical to the LS FTRs but just naphthalene was replaced by $100 \mathrm{mg} / \mathrm{L}$ lactate as a preferred carbon source for bacteria (Acton \& Barker, 1992) to control/compare the sulfate reducing bacteria (SRB) development (identified as Lact).

FTRs were operated at ambient temperature in the following sequence of steps for three months:

1. Three PVs of argon purged Milli-Q water containing background nutrients were injected.

2. 5 PVs of argon purged $100 \mathrm{mg} / \mathrm{L}$ of $\mathrm{NaBr}$ solution was injected for tracer test analyses.

3. $\sim 50 \mathrm{PVs}$ (one month) influent solution with $\sim 4 \mathrm{mg} / \mathrm{L}$ naphthalene concentration was injected and then FTRs were stopped for one week under anaerobic saturated condition. Then FTRs were again flushed with $\sim 50$ PVs (one month) of $\sim 13 \mathrm{mg} / \mathrm{L}$ 
naphthalene solution. Naphthalene concentrations of 4 and $13 \mathrm{mg} / \mathrm{L}$ were chosen according to field conditions (Shafieiyoun et al., 2018). Lactate concentration was $100 \mathrm{mg} / \mathrm{L}$ in the Lact FTR.

\section{RESULTS AND DISCUSSIONS}

The results from tracer tests indicated the effective porosity for the LS1 and LS2 FTRs are 37 and 44\%, respectively, for BW1 and BW2 FTRs are 28 and 32\%, respectively, and for the Lact and Biocide FTRs are 39 and 62\%, respectively. The differences between the effective porosities are because undisturbed soil samples were employed in this study.

Sulfate concentration in the Lact FTR decreased to $<20 \mathrm{mg} / \mathrm{L}$ indicating the development of sulfate reducing bacteria (SRB) under experimental conditions. For the LS and BW FTRs, sulfate concentration decreased to $\sim 135 \mathrm{mg} / \mathrm{L}$ which is in the range of theoretical stoichiometry for naphthalene degradation under sulfate reducing conditions. No significant change was observed between the influent and effluent EC values. In the Biocide FTR, no physical changes were observed but the soil color in the Lact FTR became black after two weeks which can be attributed to the production of iron sulfide during SRB activities. The soil color in the LS and BW FTRs also became darker after one month of flushing.

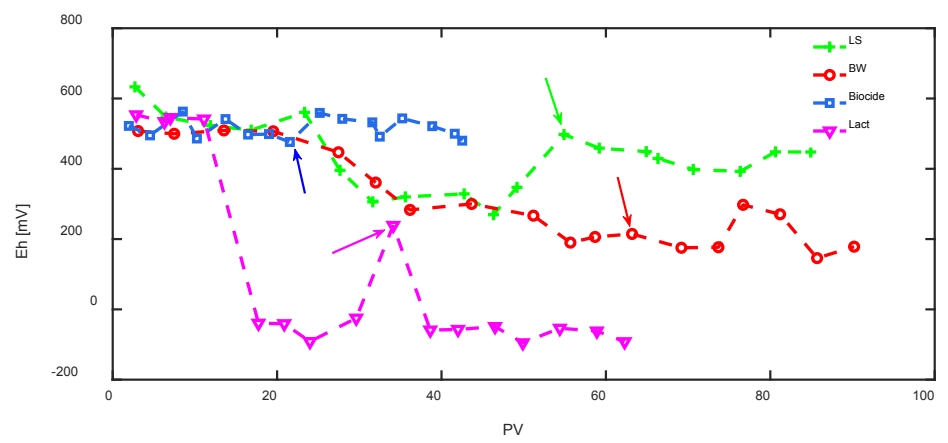

Figure 1: Effluent Eh values under low salinity (LS), brackish water (BW), biocide injection, and lactate injection (Lact). Each arrow represents the first sampling at the beginning of the second injection episode.

The color change in the FTRs was coincident with reduction in the Eh profiles (Figure 1). The Eh profile is an indicator for the redox potential and in the influent solutions was $>+500 \mathrm{mV}$. Eh values did not change in the effluent of the Biocide FTR compared to the influent solutions and remained constant indicating that microbial activities were successfully restricted. As expected, the redox potential initially dropped in the Lact FTR after $\sim 15$ PVs (two weeks) and rapidly reached to $-40 \mathrm{mV}$ indicating the enhancement of reducing conditions. Following the initial rapid drop, the effluent Eh from the Lact FTR gradually decreased to $-90 \mathrm{mV}$ after 25 PVs that was followed by minor fluctuations until the end of the experiments (62 PVs). The peak at $34 \mathrm{PV}$ is following the second injection episode and can be attributed to two weeks of no flow condition. However, following the second injection episode, again redox potential in the 
Lact FTR decreased. The Effluent Eh values in the LS FTRs dropped to $+300 \mathrm{mV}$ after $25 \mathrm{PVs}$ and following the second injection episode increased to $400 \mathrm{mV}$ after introducing the higher naphthalene concentration. For the BW FTRs, effluent Eh dropped to $200 \mathrm{mV}$ after $20 \mathrm{PVs}$ and following the second injection episode fluctuated in the range of 200 to $300 \mathrm{mV}$. A notable decrease in the effluent Eh values of the LS and BW FTRs compared to the Biocide FTR indicated the development of reducing conditions. The results from the LS and BW FTRs indicated that reducing and microbial activities were more stable under brackish water conditions which is similar to the sampling location conditions.

Effluent naphthalene concentrations are presented in Figure 2. For the Biocide FTR, effluent naphthalene concentration initially increased from $20 \%$ to $\sim 85 \%$ of the injected concentration due to saturation of soil sorption capacity. Following the second injection episode, due to an increase of injected naphthalene concentration, sorption capacity increased and effluent concentration decreased to $\sim 58 \%$. However, after saturation of the sorption capacity, effluent naphthalene concentration again increased to $85 \%$. For the LS and BW FTRs, effluent naphthalene concentration during the first injection episode initially increased from $\sim 5 \%$ to $\sim 40 \%$ due to saturation of sorption capacity while biodegradation and microbial community was not still developed. After $\sim 20 \mathrm{PVs}$, effluent naphthalene concentration for the LS and BW FTRs reached to a maximum and then decreased until the end of the first injection episode. While during the first injection episode, the LS and BW FTRs showed similar behavior, following the second injection episode, the LS FTRs were disturbed but the BW FTRs remained stable. The effluent naphthalene concentrations from the LS FTRs increased to $\sim 20 \%$ following the second injection episode suggesting that microbial activities and biodegradation were significantly disturbed by an increase in the injected naphthalene concentration. In the case of BW FTRs, effluent naphthalene concentrations after second injection episode remained below the method detection limit (MDL). It can be hypothesized that as opposed to the conventional idea that salinity can restrict biodegradation (Abed et al., 2015), the results from this study indicated that treatment efficiency was higher under brackish conditions probably because microbial community in the undisturbed soil sample was adopted to the higher salinity at the sampling location.

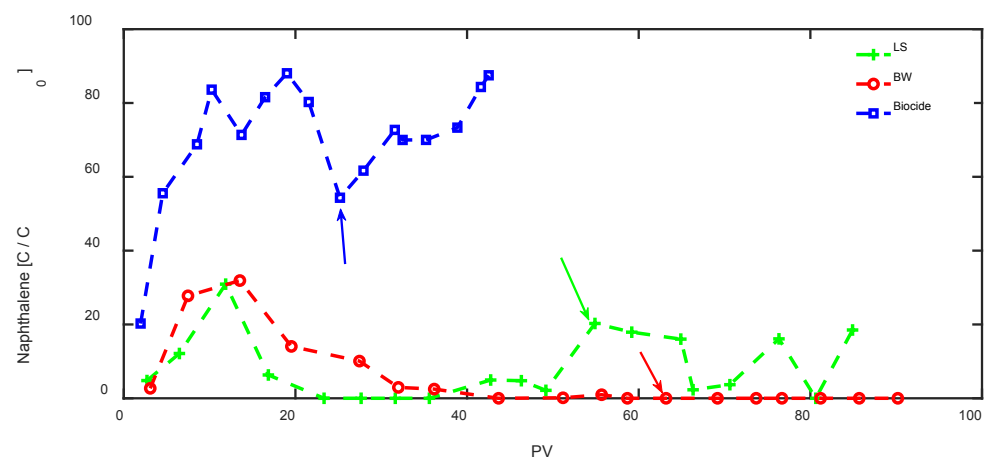

Figure 2: Effluent naphthalene concentrations under low salinity (LS), brackish water (BW), and biocide injection. Each arrow represents the first sampling following the beginning of the second injection episode. 


\section{CONCLUSION}

Our findings indicated that while for the low naphthalene concentration $(3.5 \mathrm{mg} / \mathrm{L})$, biodegradation under anaerobic sulfate reducing conditions is not significantly affected by salinity, for the high naphthalene concentration $(13 \mathrm{mg} / \mathrm{L})$ reducing conditions, microbial activity, and treatment efficiency was more enhanced under brackish water conditions probably because microbial community in the undisturbed soil samples employed in this study were adopted to the brackish water conditions at the sampling location.

\section{ACKNOWLEDGMENT}

This publication was made possible by funding from NPRP grant \# NPRP9-093-1021 from the Qatar national research fund (a member of Qatar Foundation).

\section{REFERENCES}

Abed, R. M. M., Al-Kharusi, S. \& Al-Hinai, M. (2015). Effect of biostimulation, temperature and salinity on respiration activities and bacterial community composition in an oil polluted desert soil. Int. Biodeterior. Biodegradation, Vol. 98, pp. 43-52.

Acton, D. W. \& Barker, J. F. (1992). In situ biodegradation potential of aromatic hydrocarbons in anaerobic groundwaters. J. Contam. Hydrol., Vol. 9, No. 4, pp. 325-352.

Al-Raoush, R. I. (2014). Experimental investigation of the influence of grain geometry on residual NAPL using synchrotron microtomography. J. Contam. Hydrol., Vol. 159, pp. 1-10.

Pallud, C., Meile, C., Laverman, A. M., Abell, J. \& Van Cappellen, P. (2007). The use of flowthrough sediment reactors in biogeochemical kinetics: Methodology and examples of applications. Mar. Chem., Vol. 106, No. 1-2 SPEC. ISS., pp. 256-271.

Shafieiyoun, S., Thomson, N. R., Brey, A. P., Gasinski, C. M., Pence, W. \& Marley, M. (2018). Realistic expectations for the treatment of FMGP residuals by chemical oxidants. J. Contam. Hydrol.

Thamer, M., Al-Kubaisi, A. R., Zahraw, Z., Abdullah, H. A., Hindy, I. \& Khadium, A. A. (2013). Biodegradation of Kirkuk light crude oil by Bacillus thuringiensis, Northern of Iraq. Nat. Sci., Vol. 5, No. 7, pp. 865-873.

Van De Graaf, A. A., Mulder, A., De Bruijn, P., Jetten, M. S. M., Robertson, L. A. \& Kuenen, J. G. (1995). Anaerobic Oxidation of Ammonium Is a Biologically Mediated Process. Appl. Environ. Microbiol., Vol. 61, pp. 1246-1251.

Ward, D. M. \& Brock, T. D. (1978). Hydrocarbon Biodegradation in Hypersaline Environments. Appl. Environ. Microbiol., Vol. 35, pp. 353-359. 